Amir R. Dehdashti

Hana Abouzeid

Shahan Momjian

Jacqueline Delavelle

Bénédict Rilliet

\section{Occipital extra- and intracranial lipoencephalocele associated with tectocerebellar dysraphia}

Received: 23 May 2003

Published online: 17 February 2004

(C) Springer-Verlag 2004

Commentaries on this paper are available at http://dx.doi.org/10.1007/s00381-0030861-7, http://dx.doi.org/10.1007/s00381003-0862-6, http://dx.doi.org/10.1007/ s00381-003-0863-5, http://dx.doi.org/ 10.1007/s00381-003-0864-4, http:// dx.doi.org/10.1007/s00381-003-0865-3 and http://dx.doi.org/10.1007/s00381-0030866-2

A. R. Dehdashti $(\bullet) \cdot$ H. Abouzeid ·

S. Momjian · B. Rilliet

Department of Neurosurgery,

Geneva University Hospital,

Rue Micheli-du-Crest 24,

1211 Genève 14 , Switzerland

e-mail: amirdehdashti@hotmail.com

Tel.: +41-22-3728203

Fax: $+41-22-3728225$

J. Delavelle

Division of Neuroradiology,

Geneva University Hospital,

Rue Micheli-du-Crest 24,

1211 Genève 14 , Switzerland

\begin{abstract}
Objects: Tectocerebellar dysraphism was first described by Padget and Lindenberg, together with occipital encephaloceles, cerebellar midline defects, tectal beaking, posterior kinked and displaced brainstem, and inverted cerebellum. We present a unique case of lipoencephalocele associated with tectocerebellar dysraphia and discuss the etiologies of both pathologies. The importance of the developmental comprehension of posterior fossa malformations is stressed.

Case report: A 9-month-old girl in good health was referred for a huge occipital mass. On local examination, the patient had a rounded mass about $10 \times 12 \mathrm{~cm}$ in size, covered by alopecic skin, with a small eccentric dimple without any discharge. Magnetic resonance imaging revealed a lipoencephalocele with an intra- and an extracranial part, associated with tectocerebellar dysraphia with no as-
\end{abstract}

pect of inverted cerebellum as originally described in the tectocerebellar dysraphia. Resection of the extracranial part of the lipoma was performed for esthetic reasons. The intracranial part remained in situ. Conclusion: The association of lipoencephalocele and tectocerebellar dysraphia is extremely rare. The functional prognosis seems to be less severe for this combination than for the isolated tectocerebellar dysraphia. This association favors the dysraphic theory for the embryogenesis of the lipoma. It seems safe to restrict the surgery of this bizarre malformation to its external part.

Keywords Encephalocele . Mesencephalon - Intracranial lipoma . Tectocerebellar dysraphism

\section{Introduction}

Cephaloceles are a part of the family of neural tube defects. They signify a congenital defect in the cranium and dura with extracranial herniation of any intracranial structure $[4,5]$. Cephaloceles are subdivided into four types: cranial meningoceles, cranial glioceles, cranial meningoencephaloceles, and atretic cephaloceles $[4,5]$. The frequency has ranged from 1 per 2,400 to 1 per 12,500 live births; the true incidence has been underrated in stillborns. The latter is probably attributed to massive malformations causing early pregnancy losses. Cephaloceles may occur as isolated malformations or together with other abnormalities, and associated abnormalities are present in up to $50 \%$ of cases. Occipital and parietal cephaloceles appear to be related to neural tube defects. In a series by Naidich et al., $7 \%$ of children with occipital encephaloceles showed concurrent myelomeningoceles [16]. Consistency may be cystic to mixed solid-cystic. Cephaloceles are typically covered in skin, the base covered in hair and a variable portion of the sac tends to thin out toward the dome of the sac. 
Rokitansky (cited in [7])first described the intracranial lipoma, which generally represents a benign lesion. Although its pathogenesis is controversial, this abnormality is believed to be congenital in origin. Lipomas have been reported in association with a number of congenital malformations. These lesions have a predilection to occur at or close to the midline, and the corpus callosum is the site of occurrence in $50 \%$ of cases $[8,9,19]$.

Tectocerebellar dysraphism was first described by Padget and Lindenberg in 1972 and is associated with occipital encephaloceles, cerebellar midline defects, tectal beaking, posterior kinked and displaced brainstem, and inverted cerebellum [18].

We describe here an extremely rare case of a cephalocele with an extra- and intracranial lipoma associated with tectocerebellar dysraphism. The intracranial part of the lipoma was anchored to a beaked and elongated quadrigeminal plate associated with a straight brainstem.

\section{Case report}

A 9-month-old girl was referred to the pediatric department for a huge occipital mass. Physical examination revealed a healthy infant. Neurological examination depicted symmetric and harmonious arm and leg movement without any lateralization or notable neurologic deficit. Local examination of the tumor revealed a rounded mass, about $10 \times 12 \mathrm{~cm}$ in size, covered in skin, fluctuant and mobile, non-pulsating and non-transilluminating with a small, slightly eccentric dimple with no discharge (Fig. 1). Skull X-ray showed cephalofacial disproportion and bone defect. MRI revealed a protrusion through the bone defect in the occipital region (Figs. 2, 3). On a T1-weighted image, the major part of this lesion is a

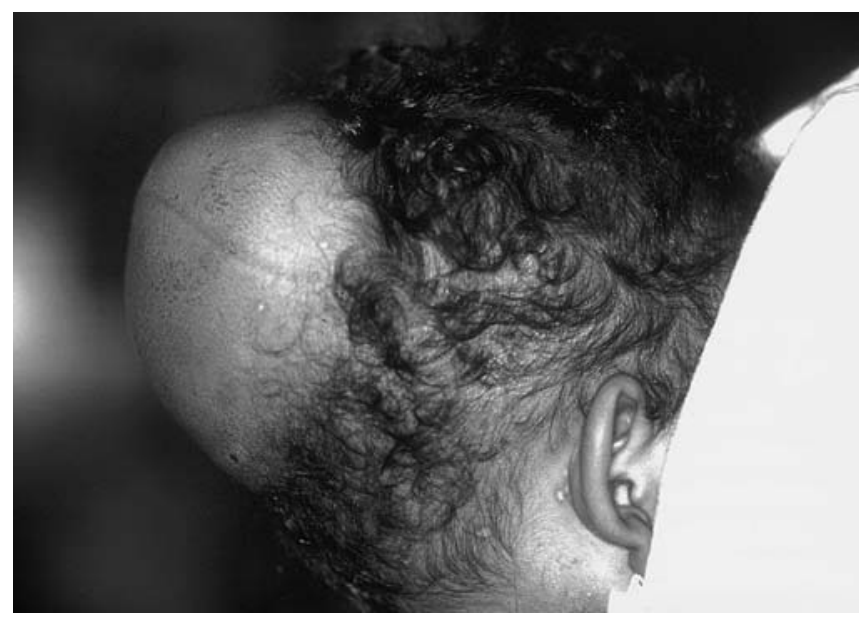

Fig. 1 Clinical aspect of the patient showing a soft alopecic bulging of the parieto-occipital region
Fig. 2 Axial T1-weighted images show the occipital bone defect and the hyperintense intracranial lipoma as well as the lipoencephalocele. An isointense structure that turned out to be of cartilaginous origin at surgery separates the two parts of the lipoma. Note the vermian agenesis, the quadrigeminal plate stretched by the lipoma and the normal aspect of the mamillary bodies and thalami

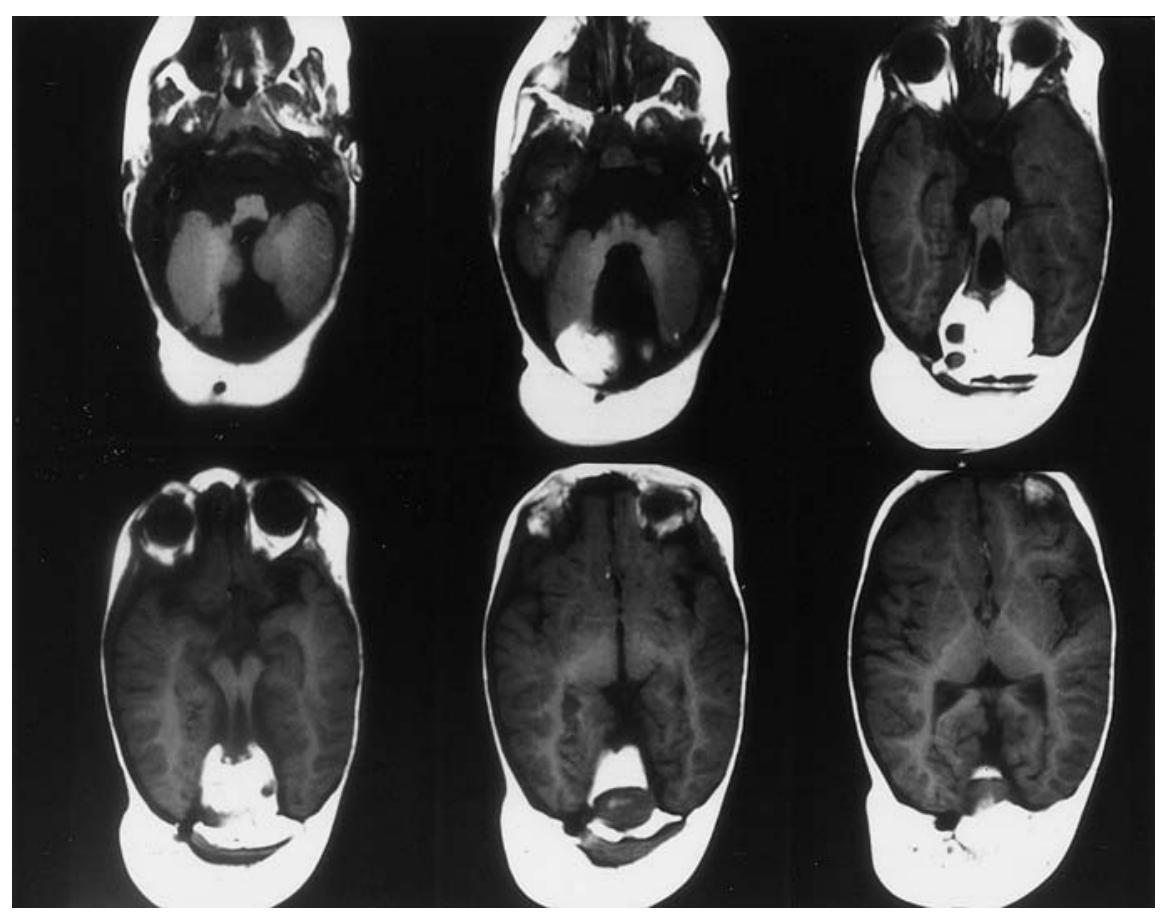

lipoma, the extracranial part (hyperintense) separated from the intracranial part by an isointense structure, which turned out be of cartilaginous material at operation (Figs. 2, 3). The vermis was absent and the quadrigeminal plate was stretched by the lipoma (Fig. 2). The curvature of the brainstem was inverted posteriorly (Fig. 3) but there was no aspect of inverted cerebellum as originally described in tectocerebellar dysraphia. The aqueduct was permeable and the supratentorial brain, including the corpus callosum, was normal.

The intracerebral lipoma was in contact with the stretched quadrigeminal plate (Fig. 2). The roof of the fourth ventricle was dehiscent with a vermian agenesis while the cerebellar hemispheres were normal (Fig. 2). Angiography was normal. Phlebography showed that the transverse and sigmoid sinus were predominant on 


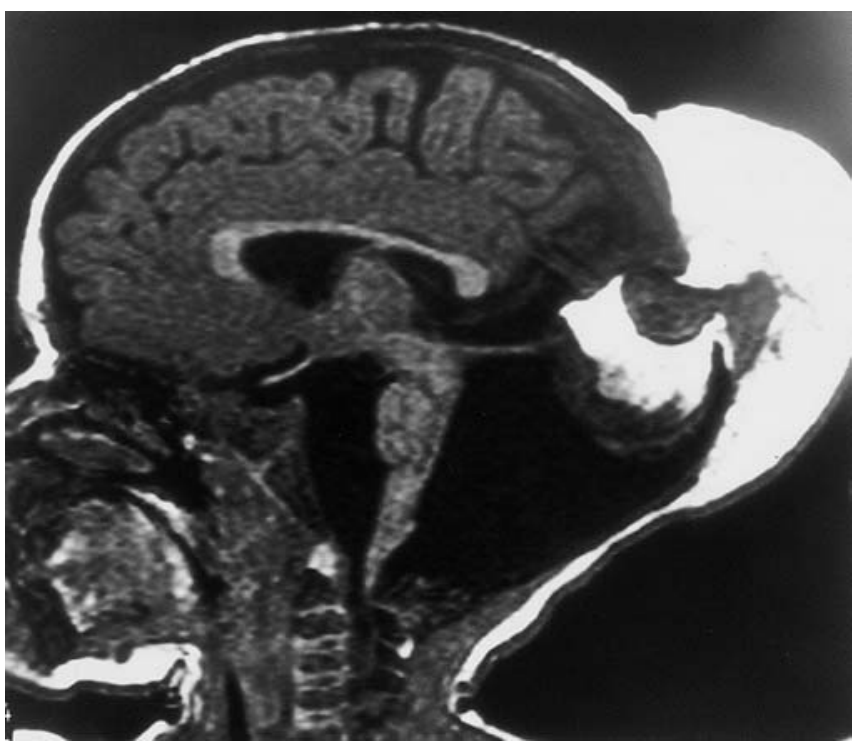

Fig. 3 Sagittal T1-weighted image demonstrates the brainstem schisis with posterior traction of the pons and midbrain, and the stretching of the tectal plate by the intracranial lipoma. The occipital cranium bifidum occultum and the lipoencephalocele are also demonstrated. Note the slight elevation of the torcular and the normal corpus callosum

the right side. The torcular was elevated and the sinus rectus was made horizontal by the tumor.

A left-sided occipital arciform incision was performed because the venous drainage was predominant on the right side. A large segment of the extracranial lipoma was cut. From the cutaneous dimple the dermal sinus was dissected and was found to end blind in the fat. The dissection was stopped at the cartilaginous structure and it was felt that it was not safe to remove the intracranial lipoma, since untethering the tectal plate could be dangerous with no real benefit for the child. The histologic examination of the extracranial mass revealed typical features of lipoma associated with cartilaginous tissue. The postoperative period was uneventful.

Eight years after the intervention, the patient is psychologically abnormal and tilts her head in a strange way. She cannot go to a normal school any more because of aggressive behavior. There are no other neurological deficits.

\section{Discussion}

Posterior cephaloceles are defined as parietal when the defect is between the bregma and the lambda, occipital when the defect arises between the lambda and the foramen magnum, and occipito-cervical when the posterior arch of the cervical vertebrae is involved. The outcome for a child with an anterior defect has been universally better than for those with a posterior defect [15]. Survival rates of $80-93 \%$ have been described for anterior defects and 40-75\% for posteriorly localized defects. Posterior defects have a worse prognosis, which is attributed to the associated hydrocephalus $[12,15]$. The etiology of the cephalocele defect remains unclear.
Environmental and genetic factors seem to play a role. Other etiologic hypotheses are malnutrition, vitamin A excess, trypan blue, $\mathrm{X}$-radiation, or folic acid antagonists $[18,21]$. Associated abnormalities are present in up to $50 \%$ of the cases.

Padget and Lindenberg published the first case of tectocerebellar dysraphia in 1972 [11] and since then about 20 cases have been reported. The dysraphia may be associated with an occipital encephalocele, a cerebellar midline defect, a beaked deformity of the tectum, a brainstem kinked with posterior displacement, or an inverse cerebellum $[6,11,13,16,20]$. Elevated torcular, dysplasia of mamillary bodies, fusion of the thalami, aplasia of the corpus callosum, or cervical hydromyelia can also be found [16]. These cases are sporadic, there is a male predominance, the prognosis is gloomy, and most patients are severely retarded because of microcephaly and die within the first year of life. Those who survive may require a shunt.

The embryogenesis is not clear. Padget and Lindenberg thought that tectocerebellar dysraphia could be the missing link between the type II Chiari and the DandyWalker malformations but this remain conjectural [16]. Friede and Boltshauser have proposed four categories of developmental defects of the cerebellar vermis and have described a unique case of tectocerebellar dysraphia with occipital encephalocele [12].

The pathogenesis of cephaloceles is not yet fully defined. According to Barkovich et al., cephaloceles through the calvarium may be caused by the defective induction of membranous bone, dysgenesis of the dura, failure of the closure of the neural tube in one of the sites of primary closure, or they may be secondary to erosion of the bone generated by an intracranial mass $[1$, 2]. Tectocerebellar dysraphia probably occurs around days 33 to 44 of gestation, during Carnegie stages 14-18 [14].

By the 4th week of embryogenesis, the neural tube, as well as the anterior and posterior neuropores, are normally closed. This process begins between the third and sixth somites (future neck) and proceeds bidirectionally toward the cranial and caudal end. Recent embryological studies have shown that, in fact, the neural tube closure initiates at multiple sites in humans [22]; the closure of the anterior neuropores in particular seems to be a bidirectional event [17]. Schisis of the brainstem, as in our case, suggests that the anterior neuropore at the level of the mesencephalic-rhombencephalic transition (fourth ventricle) did not close. Nakatsu et al. have observed this type III neural tube defect between Carnegie stages 12 and 21 [17].

The presence of an intracranial lipoma has already been mentioned in two cases of tectocerebellar dysraphia in the literature $[6,13]$. Intracranial lipomas are now accepted to be congenital malformations that grow as part of the general growth of the body. They are most 
frequently found anteriorly, associated with a partial agenesia of the corpus callosum and frontonasal dysplasia with hypertelorism. Some localizations of lipomas cause specific symptoms, but they are asymptomatic in most cases [10], and were found as incidental findings before the introduction of computerized tomography [8]. Lipomas can be found in the midline through the entire neuraxis and a dysraphic origin seems to be a good explanation. The origin of non-midline lipomas is more difficult to explain. Budka considers two embryogenic hypotheses for intracranial lipomas [3]: dysraphism or dysgenesis of the meningeal and vascular mesenchyme to fat. Truwit and Barkovich are the great promoters of the latter theory and do not accept the theory of dysraphism $[18,21]$. In our case, the association of both pathologies is in favor of a dysraphic origin of the lipoma as seen in lumbosacral lipomas and lipomyelomeningoceles. It is now well known and accepted that lumbosacral lipomas and lipomyelomeningoceles can be explained by focal premature disjunction of the neural ectoderm from the superficial ectoderm with mesenchymal overgrowth and lipomatous formation. In our case, the anomaly of neurulation seems to be limited to the posterior fossa with a lipoencephalocele, occult occipital dysraphism, no split of the superior sagittal sinus, and absence of callosal agenesis. The case reported by Demaerel et al. [6] probably corresponds to a slightly larger neural tube defect involving the tentorium, with an atretic parietal cephalocele, split superior sagittal sinus, and callosal dysgenesis.

In conclusion, the association of lipoencephalocele and tectocerebellar dysraphia seems to be very rare. This association suggests multiple sites of closure defects of the neural tube and places the tectocerebellar dysraphia in the spectrum of midline dorsal dysraphia. In our case, removal was indicated for cosmetic benefit, to avoid constant irritation and ulceration, and also to eradicate any possible coexistence of a dermal sinus extending into the cranial cavity acting as a potential source of intracranial infection. Extensive surgery was considered not to be necessary in the posterior fossa and the intracranial portion of the lipoma was not removed.

Although this girl remains moderately retarded with a follow-up extending up to 8 years, the prognosis in this case seems to be less severe than that for isolated tectocerebellar dysraphia.

\section{References}

1. Barkovich AJ (1999) Congenital anomaly of the spine. In: Pediatric neuroimaging. Lippincott Williams and Wilkins, Philadelphia, pp 621-683

2. Barkovich AJ, Kjos BO, Norman D, Edwards MS (1989) Revised classification of posterior fossa cysts and cystlike malformations based on results of multiplanar MR imaging. Am J Roentgenol 153:1289-1300

3. Budka H (1974) Intracranial lipomatous hamartomas (intracranial "lipomas"): a study of 13 cases including combinations with medulloblastoma, colloid and epidermoid cysts, angiomatosis and other malformations. Acta Neuropathol 28:205-222

4. Chowdahry UM, Ibrahim AW, Ammar AH, Dawodu AH (1989) Tecto-cerebellar dysraphia with occipital encephalocele. Surg Neurol 31:310-314

5. David JD, Proudman TW (1989) Cephaloceles classification, pathology and management. World J Surg 13:349_ 357

6. Demaerel P, Kendall BE, Wilms G, Halpins SFS, Casaer P, Baert AL (1995) Uncommon posterior cranial fossa anomalies: MRI with clinical correlation. Neuroradiology 37:72-76

7. Eghwrudjakpor PO, Kurisaka M, Fukuoka M, Mori K (1991) Intracranial lipomas. Acta Neurochir (Wien) 110:124-128
8. Eghwrudjakpor PO, Kurisaka M, Fukuoka M, Mori K (1992) Intracranial lipomas: current perspectives in their diagnosis and treatment. Br J Neurosurg 6:139-144

9. Ergün R, Ökten AI, Bostanci U (1999) An unusual case of cephalocele associated with lipoma of corpus callosum. Pediatr Neurosurg 30:30-32

10. Fandino Rivera J (2001) Intracranial lipomas. Rev Neurol 32:644-650

11. Friede RL (1978) Uncommon syndromes of cerebellar vermis aplasia II: tectocerebellar dysraphia with occipital encephalocele. Dev Med Child Neurol 20:764-772

12. Friede RL, Boltshauser E (1978) Uncommon syndromes of cerebellar aplasia II: tecto-cerebellar dysraphia with occipital encephalocele. Dev Med Child Neurol 20:758-763

13. Komiyama A, Toda H, Johkura K, Kataoka M, Yamamoto I (1999) Pretectal pseudobobbing associated with an expanding posterior fossa cyst in the tectocerebellar dysraphia: an electrooculographic study. J Neurol 246:221-223

14. Lemire RJ, Loeser JD, Lecch RW, Ellsworth CA (1975) Cerebellum, in normal and abnormal development of the human nervous system. Harper and Row, Hagerstown, pp 144-163

15. McLaurin RL (1964) Parietal cephaloceles. Neurology 14:764-772
16. Naidich TP, Altman NR, Braffman BH, McLone DG, Zimmerman RA (1992) Cephaloceles and related malformations. Am J Neuroradiol 13:655-690

17. Nakatsu T, Uwabe C, Shiota K (2000) Neural tube closure in humans initiates multiple sites: evidence from human embryos and implications for the pathogenesis of neural tube defects. Anat Embryol 201:455-466

18. Padget DH, Lindenberg R (1972) Inverse cerebellum morphogenetically related to Dandy-Walker and ArnoldChiari syndromes. Johns Hopkins Med J 131:228-246

19. Rapport RL, Dunn RC Jr, Alhady F (1981) Anterior encephalocele. J Neurosurg 54:213-219

20. Smith MT, Huntington HW (1977) Inverse cerebellum and occipital encephalocele. Neurology 27:246-251

21. Truwit CL, Barkovich AJ (1990) Pathogenesis of intracranial lipomas: an MRI study in 42 patients. Am J Roentgenol 4:855-864

22. Van Allen MI, Kalousek DK, Chernoff GF, Juriloff D, Harris M, McGillivray BC, Yong SL, Langlois S, MacLeod PM, Chitayat D, Friedman JM, Wilson RD, MacFadden D, PantzerJ, Ritchie S, Hall JG (1993) Evidence of multisite closure of the neural tube in humans. Am J Med Genet 47:723-743 